\title{
AN INFORMAL POPULATION REPORT AND OBSERVATION OF PHENOTYPiC VARIANCE AND habitat of the Alabama CANEBRAKe Pitcher Plant Sarracenia alabamensis Case \& R.B. Case SubsP. ALABAMENSIS (SARRACENIACEAE)
}

\author{
NoAH D. YAwN • Helena High School $\bullet 1310$ Hillsboro Parkway $\bullet$ Helena $•$ Alabama $\bullet$ USA \\ - noah.yawn@icloud.com
}

Abstract: Varying phenotypic traits of Sarracenia alabamensis Case \& R.B. Case subsp. alabamensis (Sarraceniaceae), the Alabama Canebrake Pitcher Plant, were observed across its entire range. Listed under the U.S. Endangered Species Act, this rare, endemic species is currently limited to two counties across central Alabama. There is an undocumented phenotypic variability concerning pigmentation in five populations of Sarracenia alabamensis subsp. alabamensis across central Alabama. There appears to be higher levels of pigmentation in $<5 \%$ of plants, characterized by a bilateral, interior ventral patch of anthocyanin pigmentation, terminating at the peristome and pitcher neck. Areolate and excess yellow coloration characteristics in these five populations, as well as net population status are reviewed and discussed.

\section{Introduction}

There is a total of five locations in two counties across central Alabama discussed in this report (Fig. 1), all visited within fall of 2016. Four visits occurred in the fall of 2017. Sarracenia alabamensis exhibits three main stages of growth during the active growing season. Beginning in mid to late April, the pitcher plants begin to bloom, producing multiple flowers per rhizomal growth point. Shortly after bloom, the first set of carnivorous leaves emerge, characterized by an enlarged ala, a perpendicular leaf "sail" on the anterior outside face of the pitcher tube. This enlarged ala, coinciding with significantly narrower pitcher tube diameters, results in spring growth being very floppy in nature. Later in the summer, from early June to mid July, S. alabamensis develops sturdier pitchers, displaying characteristics of typical individuals. Typical characteristics include yellowish-green coloration, fine pubescence, and maroon veining on the inside of the pitcher tube throat and lower operculum. A final growth stage is observed in S. alabamensis in the early fall months of September and October. The pitchers produced in this stage are the sturdiest, showiest, and most variative pitchers produced out of the three yearly growth stages. These are characterized by the same yellowish-green color, increased pubescence, areolate markings, and fine maroon veining on both the external and internal pitcher surfaces (Case \& Case 1974; Harper 1922). Sarracenia alabamensis reproduces both sexually and vegetatively, with large genetically identical genets resulting from extensive vegetative reproduction

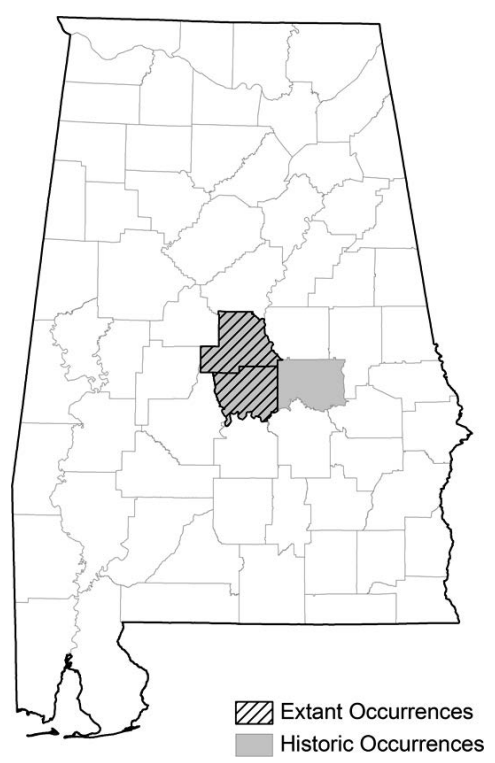

Figure 1: Known range of Sarracenia alabamensis subsp. alabamensis (U.S. Fish and Wildlife Service 2012). 
over time via rhizomal growth point division. These genets are classified by size, being referred to clumps in various instances. Large and very large genets are observed at almost all sites below, classified by an abundance of pitcher leaves, ranging from 75-150 in large genets, and 150-200+ leaves in very large genets. These clumps exhibit identical phenotypes and are therefore presumed to be genetically identical ramets in each respective clump (Murphy \& Boyd 1999).

Visits to all sites occurred during this fall growth time frame to ensure continuity in documenting the plants and their unique characteristics. Observations concerning blooms are included in some of the sites discussed below, but spring and early summer pitcher characteristics and observations are omitted. This is, in part, due to lack of notes, as well as an overall similarity in pitchers and phyllodes between all plants in this growth stage. Mature, adult pitchers and individuals are primarily reviewed. Seedling and juvenile pitchers originating from young plants tend to periodically show higher overall pigmentation and anthocyanin content, and therefore do not serve as reliable data for observations.

\section{Description, Phenotype, and Varietal Observations (Table 1)}

Site I.

Site I is managed and burned periodically by an Alabama conservation agency. Site I is alongside a seepage slope in Autauga County, Alabama, with approximately 200 individual plants (Fig. 2). An additional relict site occurs adjacent to this main population on a similar seepage slope, with large amounts of Sphagnum constituting the primary soil associate; there are approximately 15 large clumps found here. These large plants had an average of 75 leaves per clump. There were many seedlings observed at the main population, suggesting a very high seedling recruitment. A fair amount of woody shrub associates is found at both the main population and relict population, suggesting periodic burns are extremely necessary for the site's continued success. Resulting from the isolation of this site from human development, as well as being permanently protected by a conservation agency, this site does not have any immediate human impact concerns, quintessential to site viability.

The foremost and largest population at this location exhibits a whole array of variations. There is a large number of plants that display the well-known faint areoles in late summer pitchers (Case \& Case 1974). This areolate characteristic is defined in S. alabamensis to be faint, thinner patches, limited to the top third of the pitcher, that allow light to enter the pitcher. This is seen in Sarracenia

\begin{tabular}{|l|c|c|c|c|c|}
\hline \multicolumn{6}{|l|}{ Table 1. Sarracenia alabamensis phenotype population data. } \\
\hline Population & $\begin{array}{c}\text { Approximate } \\
\text { number of } \\
\text { individuals }\end{array}$ & $\begin{array}{c}\text { Plants with } \\
\text { throat patch } \\
\text { present }\end{array}$ & $\begin{array}{c}\text { Plants with } \\
\text { increased } \\
\text { pigmentation } \\
\text { (coppery-red) }\end{array}$ & $\begin{array}{c}\text { Plants with } \\
\text { increased } \\
\text { pigmentation } \\
\text { (ornate venation) }\end{array}$ & $\begin{array}{c}\text { Plants with } \\
\text { lighter flower } \\
\text { color variance }\end{array}$ \\
\hline Site I & 200 & 0 & 0 & $* 20$ & 4 \\
\hline Site II & 75 & 0 & 0 & $* 30$ & N/A \\
\hline Site III & 25 & 0 & 3 & $* 20$ & N/A \\
\hline Site IV & 3 & - & - & - & N/A \\
\hline Site V & 100 & 6 & 4 & $* 30$ & N/A \\
\hline
\end{tabular}

(*) an approximate number was recorded.

(N/A) visits did not occur during flowering.

(-) data were not available due to an absence of pitchers. 


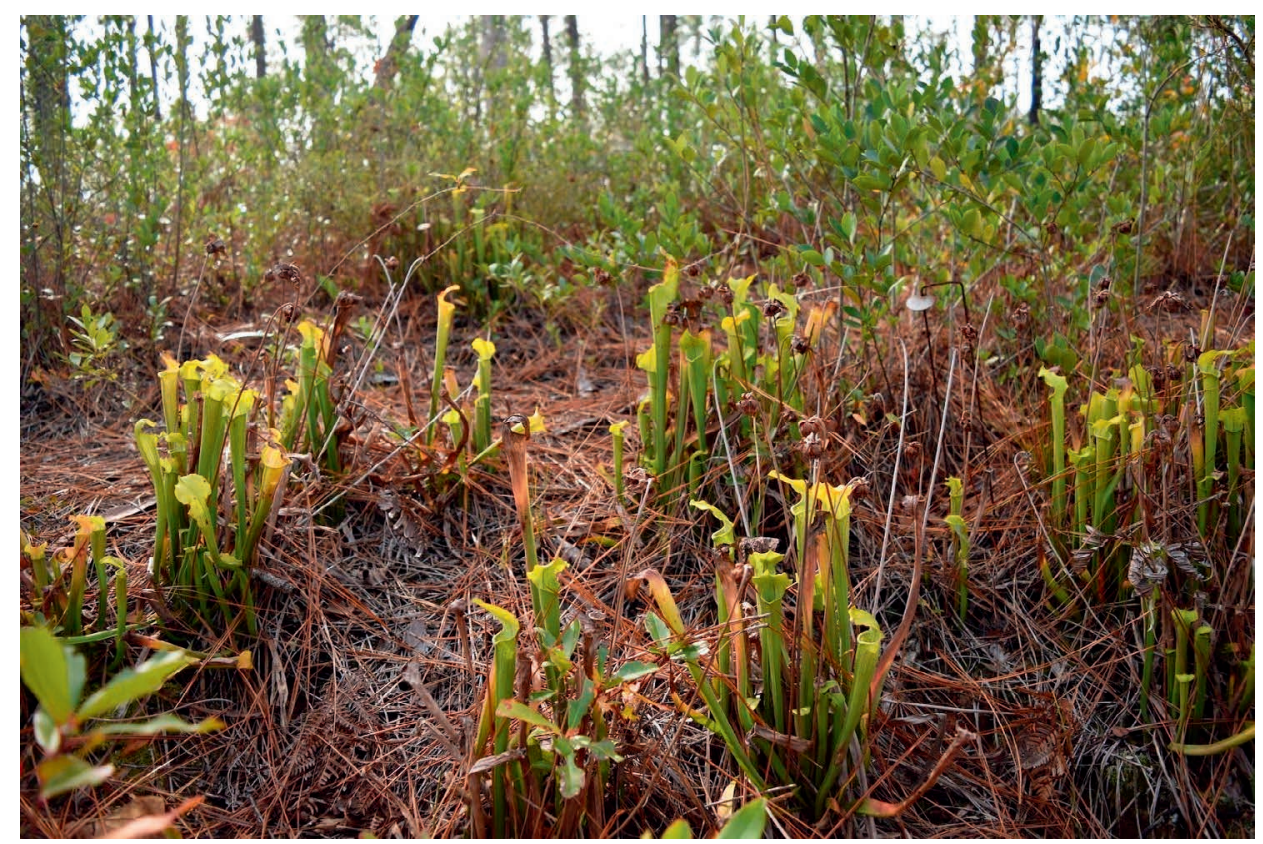

Figure 2: Site I habitat and typical Sarracenia alabamensis.

leucophylla Raf. and Sarracenia minor Walt.; in S. alabamensis this quality is far diminished in comparison to the other two Sarracenia species. Additionally, plants at this location display a wide range of size in late summer pitchers; those located in the right-hand half of the population when facing north has an overall larger size. This however, could be seasonal variance, with different seasons presumably containing individuals with larger pitchers from other areas of the population, as well as plant age. Some individuals exhibit both qualities more so than others, suggesting genetic diversity.

Specific individuals also show a variety of yellow coloration, with approximately $20 \%$ displaying significant and dense yellow pigmentation on the pitchers, as characterized by an intense, almost overlaid fluorescent green-yellow color. There appears to be uniform continuity concerning the pigmentation of the internal pitcher structure, with sparse, dark maroon veining extending from the pitcher opening, to operculum, and down the pitcher tube. Pubescence is a defined characteristic of S. alabamensis, with small hairs (similar to peach fuzz) covering the exterior pitcher tube; this is especially prominent on the upper two-thirds of the pitcher tube (Case \& Case 1974). Pitcher pubescence was very common at this site, occurring in over half of the plants.

When visiting this site in May 2017, around peak bloom time, most individuals were observed to have flowers with deep, maroon petals. However, approximately $5 \%$ of the plants here exhibited significantly lighter petal coloration-almost rose red-noticeably lighter in pigmentation when compared to the rest of the population. These individuals with such characteristics additionally had a larger yellow petal margin surrounding the edges of the petal.

Site II.

Site II in Autauga County, Alabama, is a similar seepage type environment (Fig. 3). The landowner suggests that the primary water source for this site is an underground spring; this water source al- 


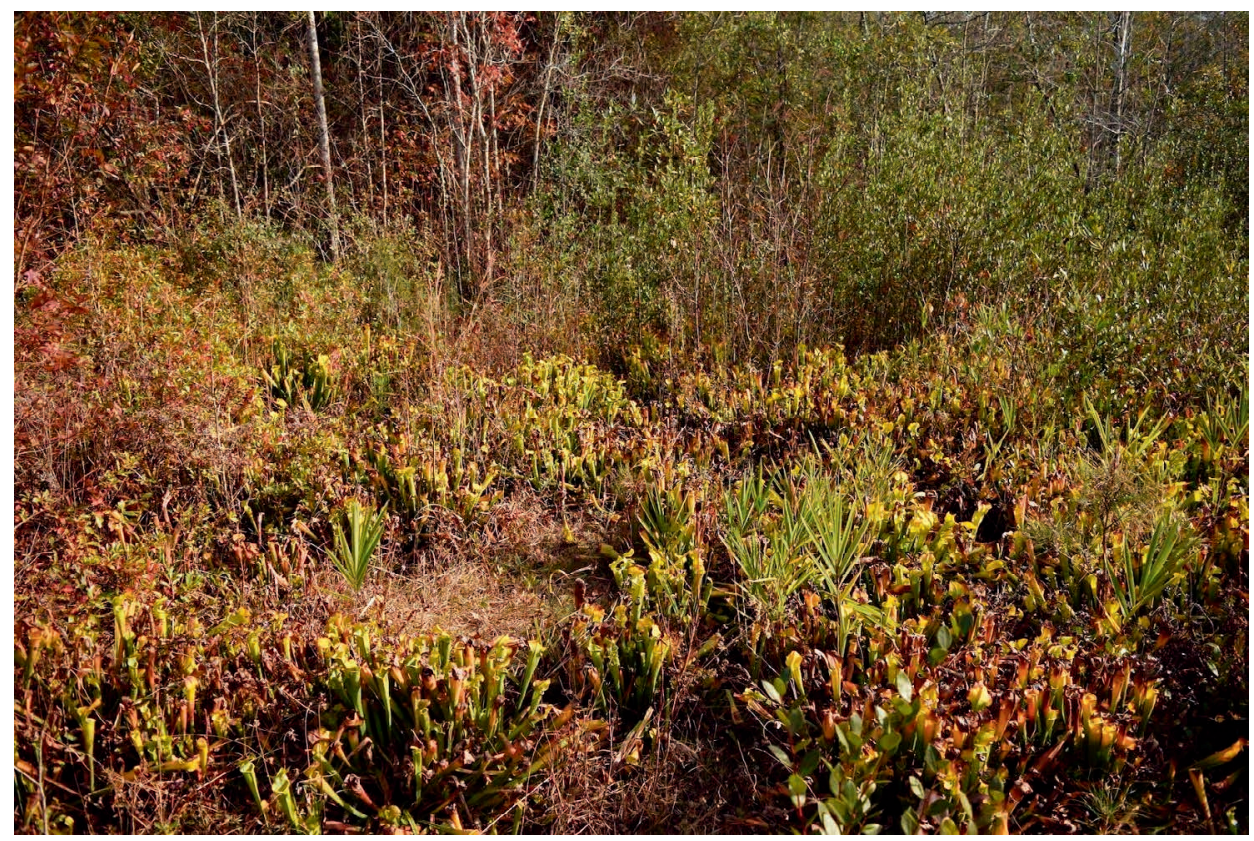

Figure 3: Largest contiguous population of Sarracenia alabamensis at Site II; population density is high here.

lows the site to have a very even hydrology with consistent and above average soil moisture, almost muck-like. The population here appears to be composed of two extremely dense groupings, divided by about $20 \mathrm{~m}$. Population density is 3-6 large genets per $\mathrm{m}^{2}$. The largest of the groupings contains an estimated 75 individuals, with the smaller containing approximately 25 . Many seedlings in their second and third years of growth were seen as well. The extremely large individual plants that grow here, with 100+ leaves per plant, suggest genetic individual genets (Murphy \& Boyd 1999).

This healthy population faces immediate challenges concerning human impact however. Nearby gravel mining, as well as tractor and vehicle disturbances next to the main contiguous population can potentially alter the site hydrology thereby harming the population. This gravel mining has created large pools of water across the adjacent land, some extremely close to the plants. However, the current landowner appears to be extremely enthusiastic and proud of the naturally occurring plants on his property and has taken measures to ensure protection of the site through conservation easements and cooperative management. As a result of past and potential human impact, this site is in need of further protection to ensure site viability.

Site II contains a large number of $S$. alabamensis, characterized by the extremely dense populations. The estimated 75 individuals exhibited large genet qualities, with anywhere from 50 to 125 leaves being counted on each plant. To a lesser extent, there was variability in plants, but not to the degree as seen at other sites. An overall uniformity in areolate pitchers was observed, with an estimated $70 \%$ of individuals exhibiting this characteristic. Yellow pitcher and veining pigmentation was uniform as well; outliers were observed however. A handful of ornate individuals, with increased reticulation on both interior and exterior pitcher surfaces, as well as plants with lesser pigmentation, with very little reticulated veins, were present. Such qualities being uniform in distribution at this site suggest slightly lower genetic population diversity in comparison with other 


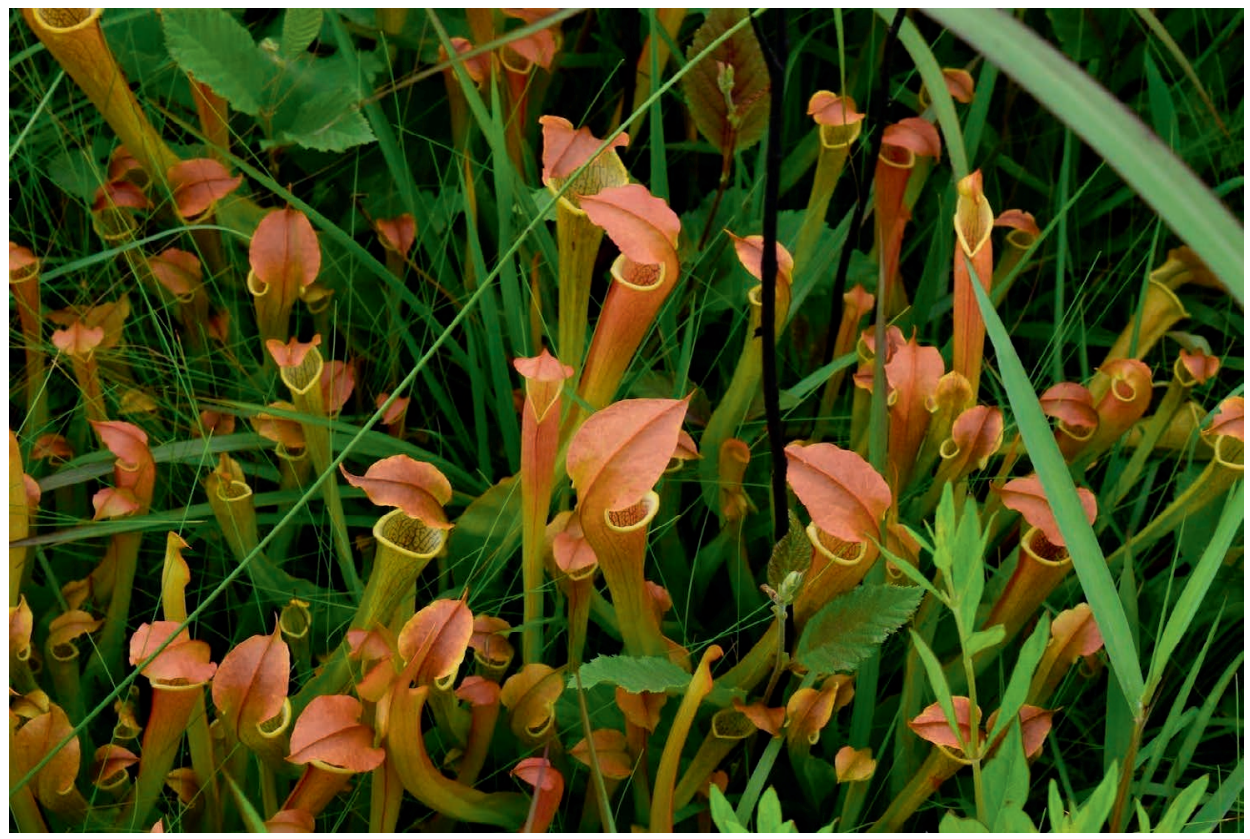

Figure 4: Early summer pitcher growth on a red genet "clump" at Site III.

populations. However, there is healthy seedling recruitment at this locale, notably in disturbed soil areas, such as tracks made by vehicles in the wet soil.

Conversely, the overall late summer pitcher size was interestingly larger than previously documented sites. Measured pitcher tube length was between $30 \mathrm{~cm}$ and $42 \mathrm{~cm}$, with the larger individuals displaying areolate characteristics more so than not. At this population, areolates appear to occur in the plants having larger pitchers in late summer. Additionally, pubescent pitchers were extremely common and uniform at this locale, with an overall majority of plants being pubescent.

Site III.

A streamside bog houses the Canebrake Pitcher Plants at Site III, growing adjacent to a nearby wetland and creek (Fig. 4). The ground and substrate appear to be consistently moist, with a hydrology gradient present. The plants here grow in a "band" in this gradient, with approximately 25 individuals present. This site's plants exhibit clumping behavior, characterized by numerous rhizomal growth points arranged in a circular pattern. These genets can have plants growing in a solid, contiguous clump, or in older individuals, have plants in a ring, with old rhizomal material not being present in the center (Murphy \& Boyd 1999). Genets at this site have anywhere from 75 to 200+ leaves per clump. Concerning the population's reproduction, there were zero seedlings observed at this site, searched for on multiple occasions.

The landowner said in 2016 that the site had not had a controlled burn in over five years. A controlled burn was conducted in early 2017, and by the fall of 2017, individual clump health at the site appeared to be in good condition due to the lack of woody shrub undergrowth. In fall 2017, there appeared to be a high frequency of deer and or other animal damage to the plants' increased seed pod and flower stalk production. Additionally, with this site being within $100 \mathrm{~m}$ of the landowner's residence, as well as less than $30 \mathrm{~m}$ from a livestock pasture, outlook on site viability appears to be 
moderate. The presence of a beaver dam has altered the creek hydrology upstream and although not impacting the population directly, has created yet another challenge concerning this site. However, the habitat is extremely healthy, and although challenging, could be a viable site with continued periodic burning and management.

Located on the margin of a healthy wetland ecosystem, this population is situated on a hydrologic gradient. On the periphery of a wetland habitat with numerous aquatic plants, this area is in a transition zone from extremely wet to moderately dry. There are both woody shrubs and bog associate plants present. Plants here appear to grow in a wetness band of about $15 \mathrm{~m}$. All visits to this site have revealed consistent soil moisture, with visible water pools in areas on the edge of this gradient. The Canebrake Pitcher Plants at this location display a large margin of phenotypic variance, with a great variety of pitcher appearances observed. The well-known and defined areolate characteristic, common to all $S$. alabamensis, is found here on approximately $50 \%$ of the individuals, with a few clumps displaying extremely prominent areoles on late summer pitcher tubes. This is limited to the top third of the tube, terminating just before the operculum (Case \& Case 1974). Interestingly, pitcher pubescence was not very common at this locale, with approximately $30 \%$ of genets possessing pubescence.

However, the most interesting feature that the Canebrake Pitcher Plants consistently exhibit at this site is the presence of high amounts of (red) anthocyanin pigmentation in a handful of individuals. Three mature clumps were found to exhibit pigmentation, with one displaying very coppery-red pigmentation, and two displaying an overall bronze coloration, darker than typical individuals, with an infused copper color extending up the exterior surface tube and the operculum. Note: during both an early summer visit and late summer visit, the clumps exhibited this reddish coloration on all pitchers, not limited to a select number of pitchers. Young and old pitchers had a similar degree of pigmentation. Therefore, this feature is concluded to have genetic influence and not environmental factors.

Moreover, each genet at Site III appears to possess individually unique characteristics, suggesting that each is composed of between one and three genetically unique individuals. The large variety of traits in each individual grouping of $S$. alabamensis at this site therefore imply significant genetic diversity.

\section{Site IV.}

Site IV in Chilton County, Alabama, is an extremely small site, with an estimated three individuals present in 2017 (Fig. 5). The site appears to be a stream-associated wetland environment, with a drainage stream and horse pasture in close proximity to the plants. The human impact on this site is extremely high, creating more of a novelty, relict site than anything. A road is very close to the location of the plants, less than $30 \mathrm{~m}$ away. Horses and livestock have grazed on the edge of the site, albeit protected by a simple wooden fence. Factoring these impacts in, as well as a large presence of dense grasses and woody shrubs, further continuance of this population does not appear to be likely.

This critically threatened site contains approximately three individual S. alabamensis plants, all observed without active pitchers at the time of visit. The only leaves present on the plants were noncarnivorous phyllodia (Fig. 5). However, an interesting characteristic of the few plants found here is that the phyllodia are analogous to that of Sarracenia flava L. or Sarracenia leucophylla. These phyllodes are characterized by being erect, sturdy, and wide, approximately 3.5 to $4 \mathrm{~cm}$ measured at the widest point on each phyllode; this is significant because typical phyllodia are 2.5 to $3 \mathrm{~cm}$ wide. Additionally, the phyllode length was greater, being 20 to $25 \mathrm{~cm}$, versus typical lengths of 13 to 17 $\mathrm{cm}$. Typical individuals have less sturdy phyllodia. Viability of this site appears to be novel, due to 


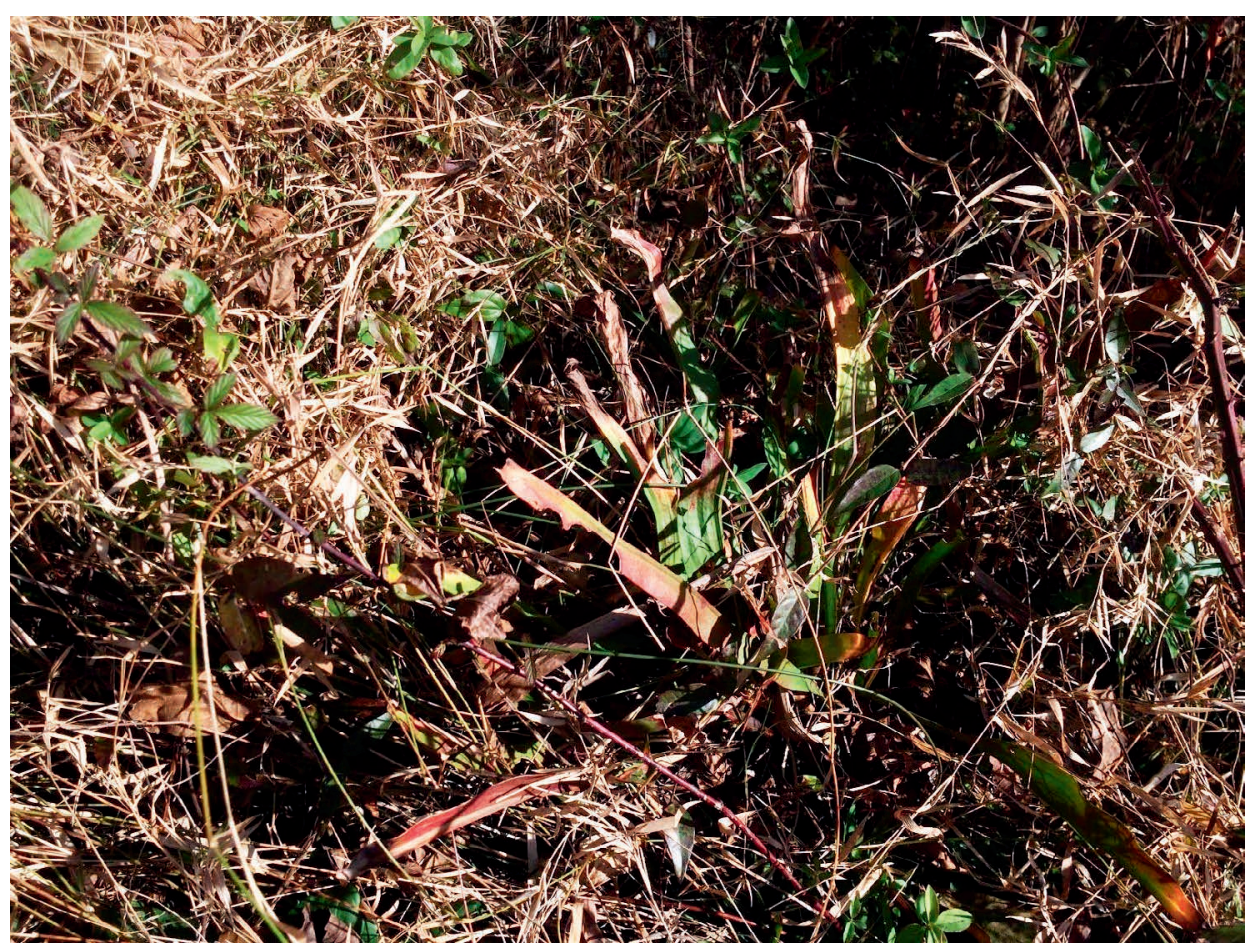

Figure 5: Site IV phyllodia of Sarracenia alabamensis.

the extremely developed surrounding landscape, significant horse and livestock influence, as well as severe habitat fragmentation.

Site V.

Site V is located in Autauga County, Alabama. This site is estimated to be at the presumed southernmost edge of the natural $S$. alabamensis range. The site features a seepage slope having a sharp topographic incline with consistent soil moisture. An estimated 100 individual plants are located on this steep slope. An extremely high amount of seedling recruitment was observed, with dense numbers of seedlings (approximately 10 per $\mathrm{m}^{2}$ ) located in places not inhabited by dense undergrowth plants. Human impact for this site is minimal, especially considering its relatively recent discovery. It is isolated and remote; therefore, disturbed hydrology and other human impacts are not prevalent at this site. Site viability appears to be extremely positive.

At this locale, there is a fair amount of variance in pitcher diversity, with typical and ornate individuals observed (Fig. 6). These ornate individuals are classified by greater pigmentation and reticulate venation located in the interior of the pitcher tube and operculum.

In addition to ornate individuals, a small number of individuals, an estimated $10 \%$ at this site, exhibited the similar red-copper coloration of those at Site III. These pitchers contained the pigmentation on all outer surfaces of the pitcher tube, extending well onto the operculum and terminating at the tip. The peristome surface was a light yellow, as was the pitcher opening and neck. On all coppery individuals, the pitcher neck exhibited the same standard maroon throat venation. Note: these coppery pitchers were both young and aged pitchers, estimated to range between less than 


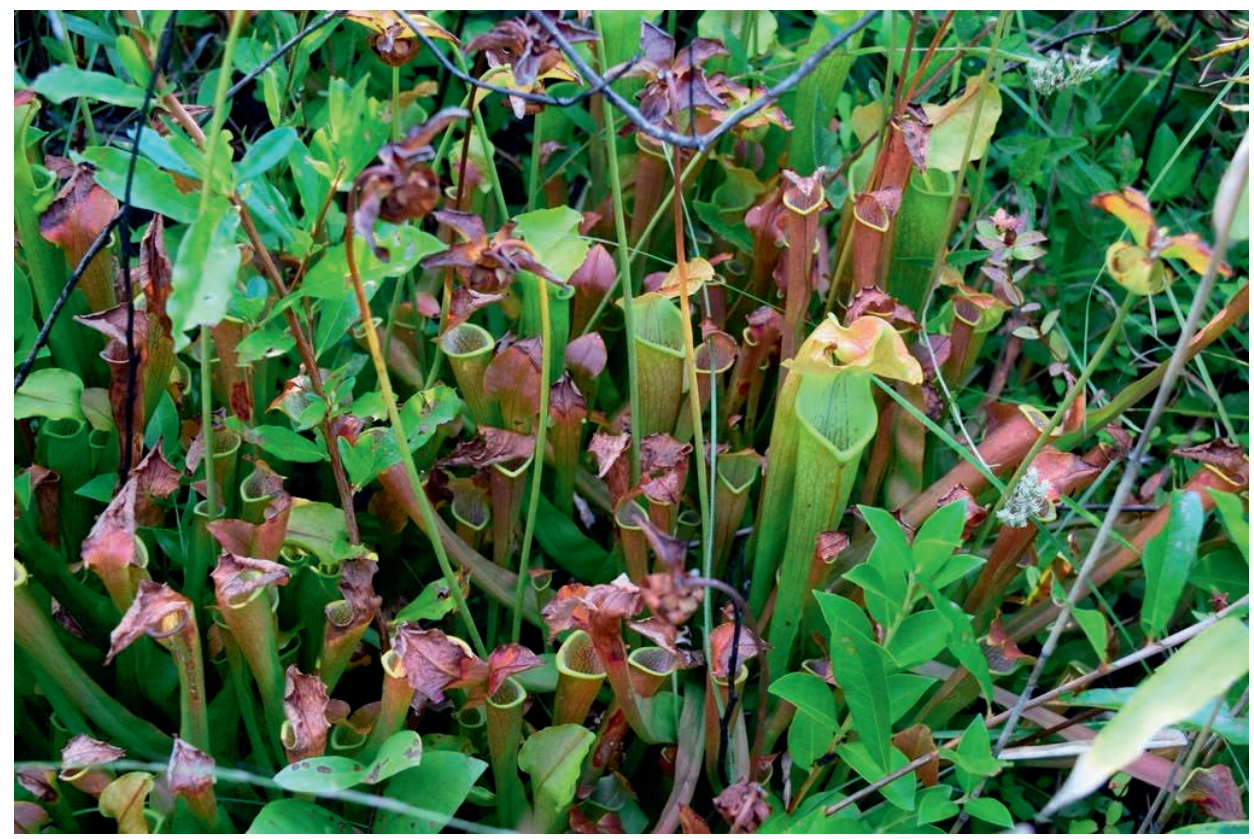

Figure 6: Extremely coppery-red pigmented Sarracenia alabamensis individual at Site V, with a typical individual growing in the center of the foreground genet.

a week to three or five weeks old at the time of visit. Young pitchers tend to display more coloration, decreasing with pitcher age. However, on these plants, this coloration does not fade with older leaves.

Moreover, a characteristic of this site is that on very few plants, there seems to be an extremely unique trait, not found at any of the other four sites mentioned above. A darker purple-maroon bilateral throat patch (Fig. 7) was seen on typical and copper individuals alike. This throat patch is located on the inside ventral surface of the pitcher opening, extending into the neck and around to the post-interior pitcher tube surface. The peristome on all of these individuals was a stan-

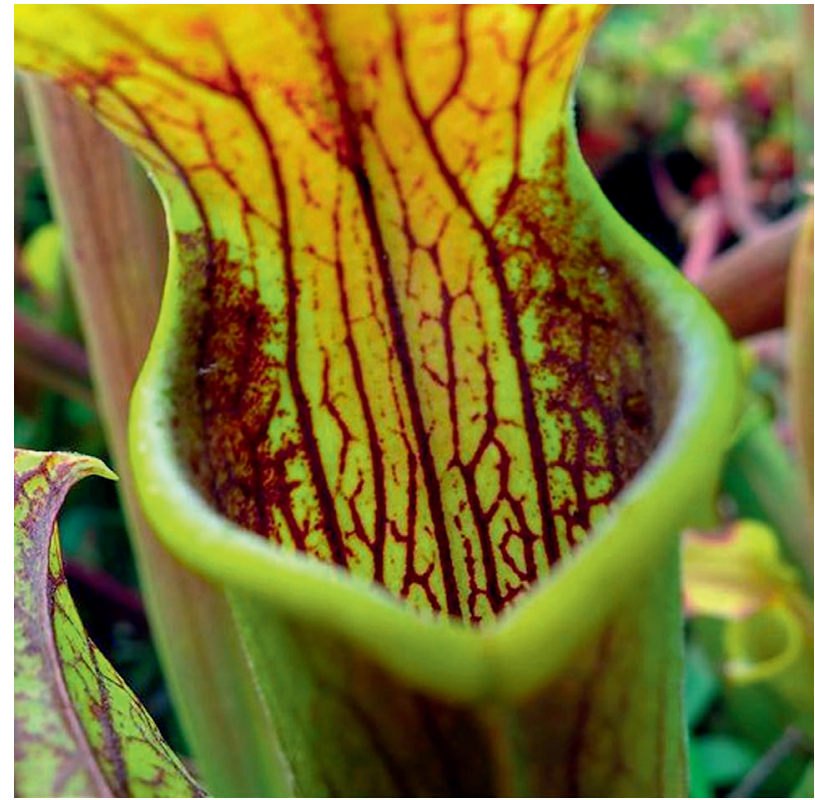

Figure 7: Extreme pigmentation of Sarracenia alabamensis with throat patch clearly visible. Plant in cultivation under the name "AL0002" from the ICPS 2001 Sarracenia Distribution Project. Photo by Michael Wang. 
dard green color. These purple throat "patches" exhibited what appeared to be elevated nectar production, suggesting that this might have insect-attracting properties. Taking in the above factors into account, there appears to be a high amount of genetic diversity in this population, especially in light of the presence of this unique throat coloration.

\section{Discussion}

A purple-maroon throat patch is occasionally found on the ventral interior surface of the pitcher tube, terminating before the interior posterior pitcher tube surface and extending no more than past the peristome (Fig. 7). This patch exhibits what appears to be elevated nectar production in observed individuals and suggests insect-attracting properties. This throat patch appears to be extremely uncommon and is not observed in all naturally occurring populations of $S$. alabamensis. Plants from Autauga County, Alabama, appear to be more prone to possessing this throat patch. There is an additional known site having plants with this pigmentation, but this additional site is not included in this report because it was not visited.

Upon further research, Internet searches, speaking with various members of the conservation community, and seeing private collections, the presence of the throat patch seems to be significant. Birmingham Botanical Gardens (BBG) is in partnership with a private conservation alliance, which has allowed BBG to house a safeguarded population of $S$. alabamensis. These safeguarded plants reportedly originate from the unvisited population in Autauga County, mentioned above. Most individuals in this collection are approximately 5 to 7 years old and are considered vegetatively young but mature, indicated by a high amount of flower production. However, there was one individual of an estimated 40 that quite noticeably exhibited this prominent throat patch. This individual had five mature, fall growth pitchers, all exhibiting the throat patch pigmentation.

Michael Wang, a private Sarracenia collector in California, known for his cutting-edge cultivation skills and meticulous record keeping, obtained an individual Sarracenia alabamensis from the 2001 International Carnivorous Plant Society Sarracenia Distribution Project (Rice 2003), catalogued as "AL0002". This plant, although grown in ideal cultivation conditions, exhibits a very strong throat patch (Fig. 7). Taking this into account, this characteristic could be one that appears more frequently in optimal growing conditions, suggesting overall site health.

The throat patch appears to be a stable characteristic that remains over the growing season, especially in the larger early summer and early fall pitchers. Questions arise about the presence of this patch, such as its purpose, if it is a recently evolved quality, and whether it could suggest strong ancestral links to other species. Further studies of this throat pigmentation, as well as higher pigmentation in coppery individuals could shed light into their effects on predation and ability to attract insects. A prey study in which individuals are measured based on coloration, presence of throat patch, pubescence, and areolate qualities across the species domain is not only feasible but could offer valuable insight into the evolutionary significance of these properties. Moreover, the extremely low frequency at which the unique throat patch occurs in natural populations of $S$. alabamensis perhaps suggests a number of things. Recessive gene expression for the throat patch that is otherwise replaced by dominant "non throat patch" genes, ancestral and historic links to other species, as well as if effective in attracting prey more efficiently, a recently evolved characteristic of the species could very well be possibilities.

This throat patch, although not analogous to Sarracenia alata (Wood) Wood, shows a striking similarity to some individuals of this species, specifically Sarracenia alata var. rubrioperculata S.McPherson \& D.E.Schnell. General similarity with Sarracenia alata var. alata is extremely no- 
ticeable; to the untrained eye one might think they are the same species. Moreover, the larger fall pitcher production characteristics seen in $S$. alabamensis are similarly seen in a number of species: Sarracenia leucophylla, Sarracenia alata, and all members of the Sarracenia rubra Walt. complex (Case \& Case 1967). With the range of $S$. alata being one relatively adjacent to that of S. alabamensis, perhaps the presence of the throat patch, coppery coloration (seen in Sarracenia alata var. cuprea S.McPherson \& D.E.Schnell), and increased size in fall pitcher production suggests recent ancestral roots connecting S. alabamensis to other members of the Sarracenia genus. Additionally, S. alabamensis historically shared the same habitat with an Elmore County, Alabama, Sarracenia oreophila (Kearney) Wherry population (extirpated), suggesting that during its evolution, it could have very well shared habitat and therefore hybridized with other members of the genus (Harper 1922).

In conclusion, Sarracenia alabamensis subsp. alabamensis presents many unsolved characteristics and qualities that are of significant value. Unlike other members of the genus Sarracenia, S. alabamensis has not been subject to much research due to its critically endangered status. Further studies delving into its phylogenetics, pigmentation genes, significance of the unique traits in this species, and the function of such could reveal further factors involving Sarracenia evolution, population dynamics, and ultimately, the continuance of this amazingly unique but critically threatened species.

\section{Additional Information}

Noah Yawn is currently a Senior at Helena High School in Helena, Alabama, who aspires to further study conservation and environmental sciences in his collegiate endeavors. This informal report is based on of his casual experience in the field, as well as informed status in the realm of Sarracenia and other native aquatic and marginal wetland plants. Based on his notes taken in the field, this report aims to discuss these observations and provide relevant conservation organizations valuable insight and recent information pertaining to this species and its native habitat. He hopes this report serves as useful insight into the diverse but increasingly critical populations of $S$. alabamensis.

Access to these populations was given by various private landowners and conservation agencies. As an aspiring photographer and naturalist, the main purpose of his visits to these secure sites were to photograph and document $S$. alabamensis for private and conservation use; while at the sites, observations and notes were recorded alongside photographs. Due to the nature of these sites, as well as specific conservation provisions and efforts to preserve the species (U.S. Fish and Wildlife Service 1992, 2012), listed under the Endangered Species Act, specific location data and or information is not included in this report.

\section{References}

Case, F.W., and Case, R.B. 1974. Sarracenia alabamensis, a newly recognized species from central Alabama. Rhodora 76: 650-665.

Case, F.W., and Case R.B. 1976. The Sarracenia rubra complex. Rhodora 78: 270-325.

Harper, R.M. 1922. Some pine-barren bogs in central Alabama. Torreya 22: 57-60.

Murphy, P.B., and Boyd, R.S. 1999. Population status and habitat characterization of the endangered plant, Sarracenia rubra subspecies alabamensis. Castanea 64: 101-113.

Rice, B. 2003. Sarracenia distribution program. Carniv. Pl. Newslett. 32(1): 4-7.

U.S. Fish and Wildlife Service. 1992. Recovery plan for Alabama canebrake pitcher plant (Sarracenia rubra ssp. alabamensis). Atlanta, Georgia. 21 p.

U.S. Fish and Wildlife Service. 2012. Alabama Canebrake Pitcher-Plant (Sarracenia rubra ssp. alabamensis). 5-Year Review: Summary and Evaluation. Jackson, Mississippi. 15 p. 